\title{
A Lanthanide complex for Selective Sensing of Fe (III) Ion
}

\author{
Amanda $P$ and A Zulys \\ Departement of Chemistry, FMIPA Universitas Indonesia, Kampus UI Depok, \\ Depok 16424, Indonesia
}

Corresponding author : putri.amanda61@ui.ac.id

\begin{abstract}
.
Lanthanide complex namely [ $\left.\mathrm{Ln}\left(\mathrm{Tpy}-\mathrm{NH}_{2}\right)_{2} \mathrm{Cl}_{2}\right] \mathrm{Cl}$ where Tpy- $\mathrm{NH}_{2}$ is 4-(p-aminophenyl)-2,2:6,2"terpyridine and $\mathrm{Ln}$ is Europium dan Dysprosium were synthesized. The ligan was found with reduction of 4-( $p$-nitrophenyl)-2,2:6,2"- terpyridine or $\mathrm{Tpy}-\mathrm{NO}_{2}$ and photophysical properties such as FT-IR spectra, UV-Vis absorption spectra, and luminescence properties of the complexes in the presence of various metal ions were studied. Here $\mathrm{Tpy}-\mathrm{NH}_{2}$ acts as chromophore or light-harvesting photo sensitizing antenna for lanthanide ion in this lanthanide complex. The bright luminescence in complex suggests favorable photo-induced energy transfer happens from the Tpy- $\mathrm{NH}_{2}$ antenna to the lanthanide ions to fill long-lived emissive excited states of lanthanide ions f-f transitions. The luminescence spectral profile of complexes show characteristic sharp multiple emission bands and maximum at ${ }^{5} \mathrm{D}_{0}$ $\rightarrow{ }^{7} \mathrm{~F}_{2} \mathrm{f}$-f transitions located at $614 \mathrm{~nm}$ for complekx Eu and at ${ }^{4} \mathrm{~F}_{9 / 2} \rightarrow{ }^{6} \mathrm{H}_{15 / 2}$ located at $578 \mathrm{~nm}$ for complex Dy. The Fluorescence studies revealed that this material showed a highly selective fluorescence quenching response to $\mathrm{Fe}^{3+}$ ions in liquid suspension and its fluorescence quenching response can be explained in terms of the competitive absorption mechanism.
\end{abstract}

\section{Introduction}

The determination of metal ions has continually gained tremendous attention in recent decades, these metal ions played important roles in living system and metal ion contamination poses significant risks to environmental systems[1]-[5]. As a result, the design and synthesis of chemosensors with high selectivity and sensitivity for metal ions is a domain of wide interest. Several methods, such as high performance liquid chromatography, mass spectrometry, and atomic absorption spectroscopy, have been developed to analyze the concerned targets. However, these methods suffer either from extensive, time consuming procedures or the use of sophisticated instrumentation [6]. In the last few years great 
attention has been paid to fluorescent chemosensors and many new systems were synthesized [7]. Fluorescence spectroscopy is widely used because of its high sensitivity, simple application, and lowcost instrumentation [4]. The development of specific fluorescent chemosensors for the efficient detection of metal ion analytes is one of the most important areas in supramolecular chemistry due to their fundamental role in biological, environmental, and chemical processes [8].

A great many efforts have been paid for designing and synthesizing sensors with high selectivity, sensitivity, low detection limit and instantaneous response [9].Recently, Lanthanide (Ln)-based coordination compounds, as an emerging type of multifunctional luminescent materials, have attracted extensive attraction in the last two decades because of their unique optical properties such as large stokes shifts, long lifetimes, and characteristic narrow line-like emission bands. These advantages have attracted intensive research efforts in the development of photosensitized and electrochemically driven luminescent materials and luminescent biolabels. Whereas the poor absorptivity of lanthanide ions owing to the parity-forbidden nature of the inner-shell $\mathrm{f}-\mathrm{f}$ transition is readily overcome by the introduction of chelating chromophores with large extinction coefficients. The fluorophores, such as anthracene, coumarin, benzaldehyde hydrazone and naphthalimide have been reported to be useful as fluorescent ion probes[6]. Among them, terpyridine and its derivatives have been extensively explored for their unique photophysical properties and high binding ability for various metal ions[10]. Terpyridines (Tpy) are the heterocyclic ligands, which have very high binding affinity towards trivalent metals [11]-[13]. In this respect, complexes of Tpy with lanthanides are a very interesting subject of research for their numerous applications in chemistry and physics. The ligand-to-lanthanide systems are endowed with two major advantages. One is that when excitation is made through the ligand, they solve the problem of small light absorption cross-section by lanthanide ions, that is, "antenna effect", and by complexing lanthanide ions [14]-[16]. In this paper, we demostrated the ability to detect the transition metal ions using the luminescence of lanthanide complex.

\section{Experimental section}

\subsection{Materials and method}

All solvents and reagents were used as obtained from commercial suppliers without further purification. 2-acetylpyridine, 4-nitrobenzaldehyde, $\mathrm{KOH}, \mathrm{NH}_{4} \mathrm{OH}$, Ethanol p.a, Methanol p.a, $\mathrm{NaHCO}_{3}$, $\mathrm{SnCl}_{2} .2 \mathrm{H}_{2} \mathrm{O}, \mathrm{Na}_{2} \mathrm{SO}_{4}, \mathrm{Eu}_{2} \mathrm{O}_{3}, \mathrm{HCl}$, and DMF of analytical grade were procured from Sigma-Aldrich and Merck. $\mathrm{EuCl}_{3} \cdot 6 \mathrm{H}_{2} \mathrm{O}$ were obtained by dissolving $\mathrm{Eu}_{2} \mathrm{O}_{3}$ in $\mathrm{HCl}$ solution. The solutions of metal ions were prepared from $\mathrm{MCl}_{2}$ ini DMF, $\mathrm{M}=\mathrm{Fe}^{3+} \mathrm{Co}^{2+}, \mathrm{Ni}^{2+}, \mathrm{Cu}^{2+}, \mathrm{Zn}^{2+}$. Infrared (FTIR) spectra (400$4000 \mathrm{~cm}^{-1)}$ as $\mathrm{KBr}$ pellet measured by Shimadzu 8400-S. UV-Visible spectra measured on Shimadzu UV- 2450at $298 \mathrm{~K}$. All the photoluminescent spectra in liquid suspensions were measured on Hitachi F-2000 FL spectrophotometer. 


\subsection{Synthesis and characterization}

2.1.1. Synthesis $T p y-\mathrm{NH}_{2}$. Tpy- $\mathrm{NH}_{2}$ ligand was prepared according to literature procedure and thoroughly characterized. The 4-(4-nitrophenyl)-2,2:6,2" -terpyridine $\left(\mathrm{Tpy}-\mathrm{NO}_{2}\right)$ was synthesized by Kröhnke method using aldol condesation mechanism [17].Nitro group of 4-(4-nitrophenyl)-2,2:6,2" terpyridine (Tpy- $\mathrm{NO}_{2}$ ) was consequently reduced using $\mathrm{SnCl}$ /Ethanol under $\mathrm{N}_{2}$ to form 4-(4aminophenyl)-2,2:6,2- terpyridine (Tpy- $\left.\mathrm{NH}_{2}\right)$ [13]. ${ }^{1} \mathrm{H}$ NMR $\left(500 \mathrm{MHz}, \mathrm{CDCl}_{3}\right) \delta$ (ppm/TMS): 8.73(d,2H), $8.66(\mathrm{~d}, 2 \mathrm{H}), 8.04(\mathrm{~d}, 2 \mathrm{H}), 7.89(\mathrm{~d}, 2 \mathrm{H}), 7.37(\mathrm{~d}, 2 \mathrm{H}), 6.82(\mathrm{~d}, 2 \mathrm{H}), 6.79(\mathrm{~d}, 2 \mathrm{H}) . \mathrm{UV} / \mathrm{V}$ is (DMF,298K), $\lambda \max / \mathrm{nm}: 289,328$. FTIR (KBr pellet, $\left.\mathrm{cm}^{-1}\right): 3300-3000$ (s), 1650(s), 1594(vs), 800(m).

2.1.2. Synthesis of complex $\left[\mathrm{Ln}\left(\mathrm{Tpy}-\mathrm{NH}_{2}\right)_{2} \mathrm{Cl}_{2}\right] \mathrm{Cl}(1)$. The $\left[\mathrm{Ln}\left(\mathrm{Tpy}-\mathrm{NH}_{2}\right)_{2} \mathrm{Cl}_{2}\right] \mathrm{Cl}$ was made by using generalized synthetic method according to literature [18] To a warm methanolic solution of Tpy- $\mathrm{NH}_{2}$ $(0.162 \mathrm{~g}, 0.5 \mathrm{mmol})$ was mixed dropwise a methanolic solution of $\mathrm{EuCl}_{3} .6 \mathrm{H}_{2} \mathrm{O}(0.091 \mathrm{~g}, 0.25 \mathrm{mmol})$ and $\mathrm{DyCl}_{3} .6 \mathrm{H}_{2} \mathrm{O}(0.092 \mathrm{~g}, 0.25 \mathrm{mmol})$ dissolved in minimum amount of methanol and refluxed for $24 \mathrm{~h}$. The reaction mixture was then evaporated under reduced pressure, a brown color solid crude product was collected, successively washed with diethyl ether and then recrystallized from ethanol to get desired pure product $\left[\mathrm{Eu}\left(\mathrm{Tpy}-\mathrm{NH}_{2}\right)_{2} \mathrm{Cl}_{2}\right] \mathrm{Cl}(\mathbf{1})$ yield $0,112 \mathrm{~g}$ and $\left[\mathrm{Dy}\left(\mathrm{Tpy}-\mathrm{NH}_{2}\right)_{2} \mathrm{Cl}_{2}\right] \mathrm{Cl}$ (1)

\subsection{Luminescence sensing of metal ions}

Expolaration of the fluorescence response when interacting with diffrent metal ions was tested in DMF solution containing diffrent $\mathrm{MCl}_{2}$ with the concentration of $[\mathrm{M}]=10^{-3} \mathrm{~mol} / \mathrm{L}\left(\mathrm{M}=\mathrm{Fe}^{3+}, \mathrm{Co}^{2+}, \mathrm{Ni}^{2+}\right.$, $\left.\mathrm{Cu}^{2+}, \mathrm{Zn}^{2+}\right)$.

\section{Result and discussion}

\subsection{Synthesis of the complex}

The complex $\left[\mathrm{Ln}\left(\mathrm{Tpy}-\mathrm{NH}_{2}\right)_{2} \mathrm{Cl}_{2}\right] \mathrm{Cl}(1)$ and (2) was prepared in $\sim 58 \%$ yield by reacting a methanolic solution of $\mathrm{LnCl}_{3} \cdot 6 \mathrm{H}_{2} \mathrm{O}$ with methanolic solution of $\mathrm{Tpy}-\mathrm{NH}_{2}$ in 1:2 molar ratio. 4-(4-nitrophenyl)2,2:6,2' - terpyridine (Tpy- $\mathrm{NO}_{2}$ ) was synthesized by reported procedure. Reduction of Tpy- $\mathrm{NO}_{2}$ was carried out using $\mathrm{SnCl}_{2} /$ ethanol under $\mathrm{N}_{2}$ to convert $\mathrm{NO}_{2}$ group to $\mathrm{NH}_{2}$ group. Synthetic schemes for preparation of ligand and complexes was shown by the Scheme 1. Complex 1 and 2 was found stable in solid and in solution state as well at ambient conditions. The Tpy- $\mathrm{NH}_{2}$ ligand and synthesized complex 1 dan 2 were fully characterized using ${ }^{1} \mathrm{H}$ NMR, FT-IR, UV-vis and emission studies. 


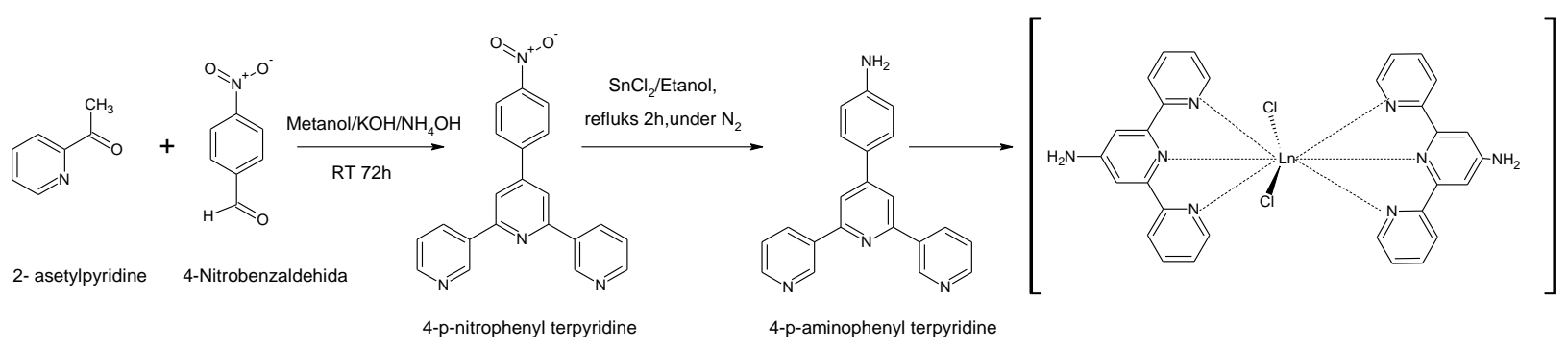

Scheme 1. Synthetic scheme for tpy-NH2 ligand and [ $\operatorname{Ln}(\operatorname{tpy}-\mathrm{nh} 2) 2 \mathrm{Cl} 2] \mathrm{Cl},[\mathrm{Ln}=\mathrm{Eu}(1)$ and $\mathrm{Dy}(2)]$.

3.2 Photophysical propertiesTpy- $\mathrm{NH}_{2}$ ligand in DMF showed intense absorption peaks centered at 289 and $328 \mathrm{~nm}$ in UV-Visible spectra due to ligand centered $\pi-\pi^{*}$ and $\mathrm{n}-\pi^{*}$ transitions (Figure. 1a). Lncomplexes showed similiar electronic spectra signature to that of ligand. Because of the weak absorption, lanthanides are usually not directly excited, but rather excited through chelated orgaic ligand. Hence, the absorption spectrum of the complex shown in reflect of the absorbtion spectrum of the ligand and not the lanthanides itself (Figure.1a). Figure.1b shows The luminescence spectral profile of complex 1 and 2 with characteristic sharp narrow band emission bands maximum at ${ }^{5} \mathrm{D}_{0} \rightarrow{ }^{7} \mathrm{~F}_{2} \mathrm{f}$-f transitions located at $614 \mathrm{~nm}$ originating from $\mathrm{Eu}^{3+}$ ion and at ${ }^{4} \mathrm{~F}_{9 / 2} \rightarrow{ }^{6} \mathrm{H}_{15 / 2}$ located at 578 $\mathrm{nm}$ originating from $\mathrm{Dy}^{3+}$ ion.

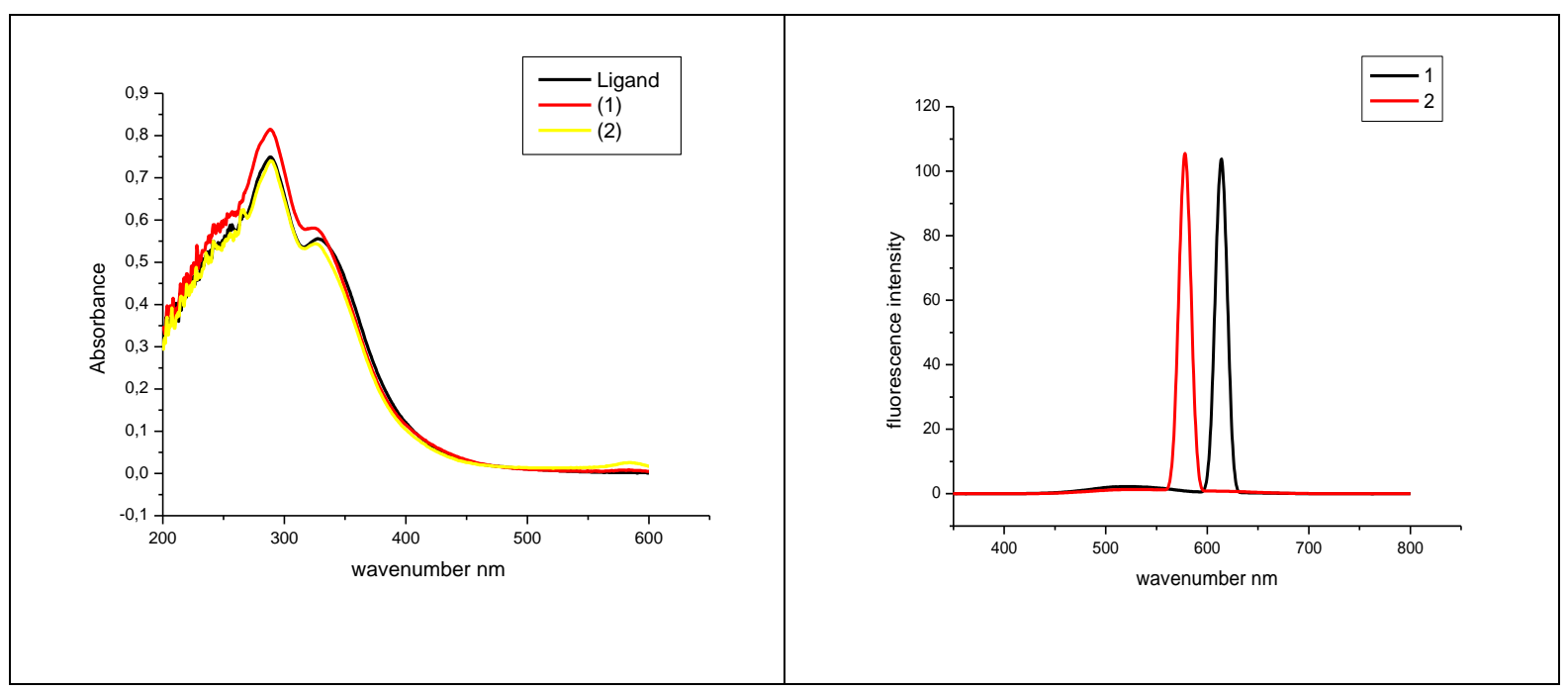

Fig. 1. (a) UV-visible absorption spectral traces of Tpy- $\mathrm{NH}_{2}$ ligand and complexes [Eu(Tpy$\left.\left.\mathrm{NH}_{2}\right)_{2} \mathrm{Cl}_{2}\right] \mathrm{Cl}$ (1) and [Dy(Tpy- $\left.\left.\mathrm{NH}_{2}\right)_{2} \mathrm{Cl}_{2}\right] \mathrm{Cl}(2)(30 \mu \mathrm{M})$ in DMF at $298 \mathrm{~K}$.(b) fluorescence spectra for complexes 1 and 2 at $298 \mathrm{~K}$. delaytime $0.1 \mathrm{~ms}$, gate time $0.1 \mathrm{~ms}, \lambda$ ex $289 \mathrm{~nm}$, slit width $=10 \mathrm{~nm},[1] 60$ $\mu \mathrm{M},[2] 30 \mu \mathrm{M}]$. 


\subsection{Luminescence sensing of metal ions}

The selectivity of the complex 1 and 2 were tested by the adition DMF solution containing diffrent $\mathrm{MCl}_{2}$ with the concentration of $[\mathrm{M}]=10^{-3} \mathrm{~mol} / \mathrm{L}\left(\mathrm{M}=\mathrm{Fe}^{3+}, \mathrm{Co}^{2+}, \mathrm{Ni}^{2+}, \mathrm{Cu}^{2+}, \mathrm{Zn}^{2+}\right)$.

Figure. 2 shows the corresponding bar diagram of lanthanide complex with and without metal ions. The figured showed that $\mathrm{Fe}^{3+}$ had more tendenced to quench the fluorescence both of the complex compared to all other metal ions studied.

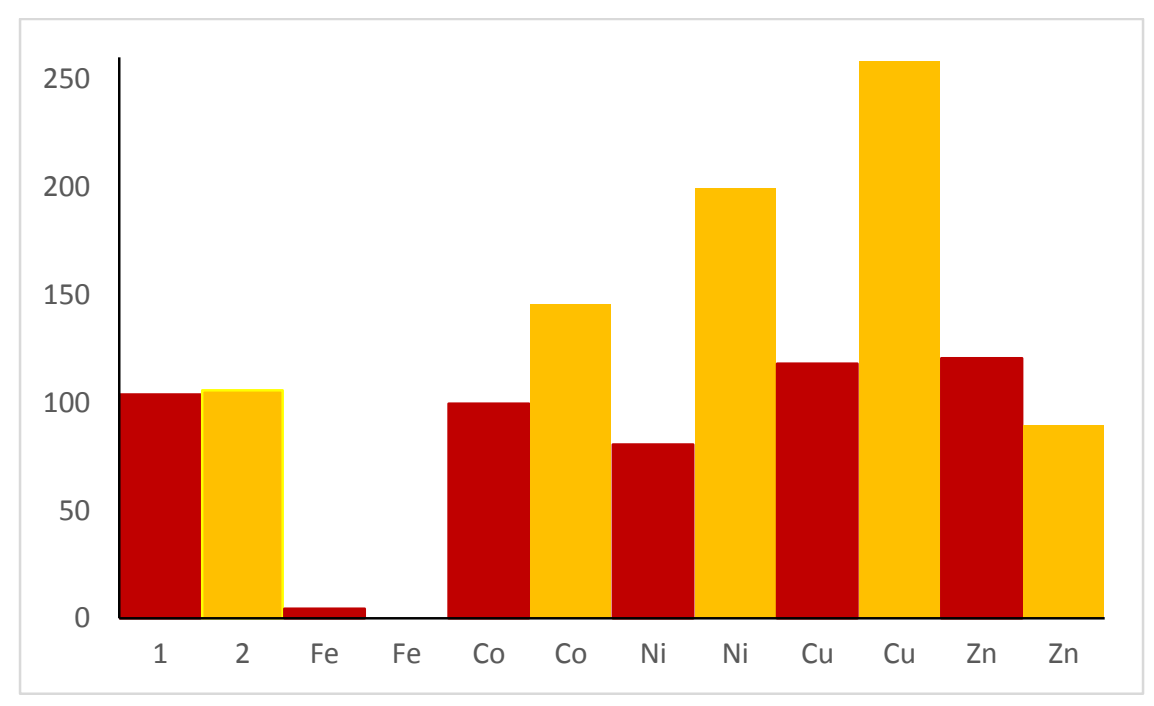

Fig 2. Selectivity profile of the complex in DMF containing diffrent metal ion $\left(10^{-3} \mathrm{~mol} / \mathrm{L}\right)$ under $\lambda_{\mathrm{ex}}$

$$
=289 \mathrm{~nm}
$$

Futher, the anti - interference experiment were also performed and the result indicated that the presence of other metal ions would not disturbed the selective sensing of $\mathrm{Fe}^{3+}$. The mixed addition of several metal ion $\left(\mathrm{Co}^{2+}, \mathrm{Ni}^{2+}, \mathrm{Cu}^{2+}, \mathrm{Zn}^{2+}\right)$ resulted in a slight reduction in fluoroscence intensity, and the emission was quenched only after the addition of $\mathrm{Fe}^{3+}$ that indicated the high selectivity of the complex towards detection $\mathrm{Fe}^{3+}$ ion.

The sensitvity of complex toward the sensing of $\mathrm{Fe}^{3+}$ ions were also analyzed. The fluorescence intensity both of complex was quenched gradually while increasing the concentration of $\mathrm{Fe}^{3+}$ ions from $0-10^{-3} \mathrm{M}$. The quenched intensity was linearly correlated with the concentration of $\mathrm{Fe}^{3+}$ from $0-10^{-5}$ $\mathrm{M}$ with linear coefficient $\left(\mathrm{R}^{2}\right)$ between the fluorescence intensity and various concentration of $\mathrm{Fe}^{3+}$ ions was 0,98645 and 0,98600 . This suggest that the complex 1 were highly sensitive toward $\mathrm{Fe}^{3+}$. Moreover the quenching effeciency of the $\mathrm{Fe}^{3+}$ ions was analyzed using Stern-Volmer relation

$$
\frac{F 0}{F}=1+K s v[Q]
$$


Were $\mathrm{F}_{0}$ and $\mathrm{F}$ is fluorescence intensitys of the complex in the absence and the presence of $\mathrm{Fe}^{3+}$ ions respectively, $\mathrm{K}_{\mathrm{sv}}$ is the Stern-Volmer quenching conctant and [Q] is concentration of $\mathrm{Fe}^{3+}$ ions. Figure 3. presents the $\mathrm{F}_{0} / \mathrm{F} \mathrm{Vs}\left[\mathrm{Fe}^{3+}\right]$ graph. The figure suggest that concentrations of $\mathrm{Fe}^{3+} 0-10^{-5} \mathrm{M}$ and the corresponding $\mathrm{F}_{0} / \mathrm{F}$ values were linearity correlated $\left(\mathrm{R}^{2}\right) 0,98727$ and 0,98603 with an intercept 1,0056 and 0,9932 respectively. The Stern- Volmer contant can be obtained by rearranging of the correlation according to equation 1 . The calculated Stern - Volmer consntant is $19,88 \times 10^{3} \mathrm{M}$.

A

B
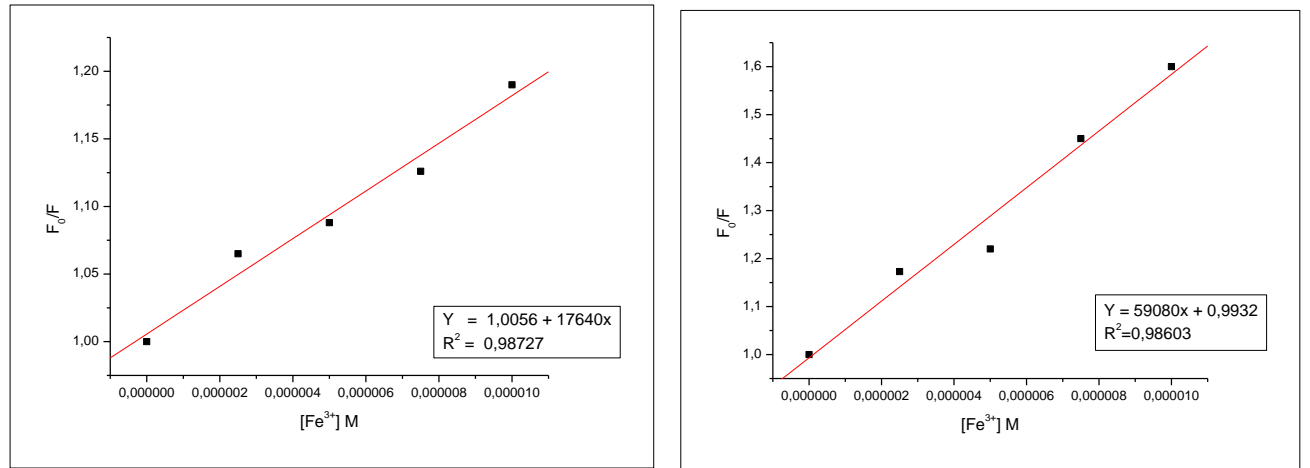

Figure 3.

The limit of detection or LOD of was calculated using following formula $3 \sigma / b$ with $b$ is slope of the linear line. The LOD as estimated to be $0,655 \mu \mathrm{M}$ and $0,27 \mu \mathrm{M}$ respectively.

\subsection{The underlying Mechanisme of luminescence quenching}

Finally, we procceded to explore the underlying mechanisme of observed fluorescence quenching in response to the presense of $\mathrm{Fe}^{3+}$ ions. The emission spectrum of the complex when additon of metal ion showed no change in wavelenght, that is indicated no molecules are chemically altered in the process. As describe above the luminescence intensity of the complex depend closely on the antenna effect thant induced the effesien energy from ligan to lanthanide ion.With this mind, we then specaluted that the luminescence quenching of the complexe might be due to competitive absorbstion of excitation energi of $\mathbf{1}$ and $\mathrm{Fe}^{3+}$ ion.To verify this possible mechanisme, the UV-Vis spectra of the solution metal ion were measured. The result shows that the absorbation band of $\mathrm{Fe}^{3+}$ ion strongly overlaps with the excitation of the complex. So we then suggest that the competitive absorption mechanisme my account for selective quenching response of 1 towards $\mathrm{Fe}^{3+}$ ion.

\section{Conclution}

In summary, A lanthanide complex namely [ $\left.\mathrm{Eu}\left(\mathrm{Tpy}-\mathrm{NH}_{2}\right)_{2} \mathrm{Cl}_{2}\right] \mathrm{Cl}(\mathbf{1})$ and $\left[\mathrm{Dy}\left(\mathrm{Tpy}-\mathrm{NH}_{2}\right)_{2} \mathrm{Cl}_{2}\right] \mathrm{Cl}$ (2) where Tpy- $\mathrm{NH}_{2}$ is 4-(p- aminophenyl)-2,2:6,2"- terpyridine were synthesized. The Complex exhibited a selective fluorescence quenching response to $\mathrm{Fe}^{3+}$ ions without the interference of the other metal ions, and this can be explained in term of the competitive absorbtion of excitation wavelenght energy 
between $\mathrm{Fe}^{3+}$ and the complex.This studies can suggest to be a promissing luminescence sensor of $\mathrm{Fe}^{3+}$ ion.

\section{References}

[1] M. A. Taher, H. Asadollahzadeh, and H. Fazelirad, "Determination of trace amounts of iron by a simple fluorescence quenching method," Anal. Methods, pp. 1-6, 2015.

[2] L. N. Neupane, E. Oh, H. J. Park, and K. Lee, "Selectively and sensitively detection of heavy metal ions in $100 \%$ aqueous solution and cells with a fluorescence chemosensor based on peptide using aggregation induced emission," Anal. Chem., 2016.

[3] X. Hui, Z. Xiwen, and D. Huiling, “A New Fluorescent Chemosensor for Metal Ions Based upon 1, 8-Naphthalimide and 8-Hydroxyquinoline," Chinese J. Chem., vol. 29, pp. 2165-2168, 2011.

[4] X. J. Feng, P. Z. Tian, Z. Xu, S. F. Chen, and M. S. Wong, "Fluorescence-Enhanced Chemosensor for Metal Cation Detection Based on Pyridine and Carbazole," 2013.

[5] L. N. Neupane, J. Park, J. H. Park, and K. Lee, "Turn-on Fluorescent Chemosensor Based on an Amino Acid for $\mathrm{Pb}$ ( II ) and $\mathrm{Hg}$ ( II ) Ions in Aqueous Solutions and Role of Tryptophan for Sensing," Org. Lett., vol. 15, no. 2, pp. 254-257, 2013.

[6] Y. Jeong and J. Yoon, "Recent progress on fluorescent chemosensors for metal ions," Inorganica Chim. Acta, vol. 381, no. 1, pp. 2-14, 2012.

[7] M. Formica, V. Fusi, L. Giorgi, and M. Micheloni, "New fluorescent chemosensors for metal ions in solution," Coord. Chem. Rev., vol. 256, pp. 170-192, 2012.

[8] K. Chang, L. Luo, E. W. Diau, and W. Chung, "Highly selective fluorescent sensing of $\mathrm{Cu}^{2+}$ ion by an arylisoxazole modified calix[4]arene,” Tetrahedron Lett. J., vol. 49, pp. 5013-5016, 2008.

[9] P. Wang et al., "Zinc(II) complex with teirpyridine derivative ligand as 'on-off' type fluorescent probe for cobalt(II) and nickel(II) ions," Inorg. Chem. Commun., vol. 18, pp. 87-91, 2012.

[10] J. Yuan and G. Wang, "Lanthanide-based luminescence probes and time-resolved luminescence bioassays R:," Trends Anal. Chem., vol. 25, no. 5, 2006.

[11] E. A. Hassan, M. L. Hassan, C. N. Moorefield, and G. R. Newkome, "New supramolecular metallo-terpyridine carboxymethyl cellulose derivatives with antimicrobial properties," Carbohydr. Polym., vol. 116, pp. 2-8, 2015.

[12] M. L. Hassan, C. M. Moorefield, H. S. Elbatal, G. R. Newkome, D. A. Modarelli, and N. C. Romano, "Fluorescent cellulose nanocrystals via supramolecular assembly of terpyridinemodified cellulose nanocrystals and terpyridine-modified perylene," Mater. Sci. Eng. B SolidState Mater. Adv. Technol., vol. 177, no. 4, pp. 350-358, 2012.

[13] S. Bo, X. Liu, and Z. Zhen, "Preparation and luminescence properties of hybrid materials containing lanthanide complexes covalently bonded to a terpyridine-functionalized silica matrix," J. Lumin., vol. 128, no. 10, pp. 1725-1730, 2008.

[14] M. H. V Werts, "Making sense of lanthanide luminescence," vol. 88, pp. 101-131, 2005. 
[15] S. Xu, W. Pei, N. Ren, L. Huang, and W. Huang, "Recent developments in lanthanide-based luminescent probes," Coord. Chem. Rev., pp. 1-12, 2014.

[16] L. Armelao et al., "Design of luminescent lanthanide complexes : From molecules to highly efficient photo-emitting materials," Coord. Chem. Rev., vol. 254, pp. 487-505, 2010.

[17] P. R. Andres et al., "New 4'-Functionalized 2,2':6',2"-Terpyridines for Applications in Macromolecular Chemistry and Nanoscience,” Eur. J. Org. Chem., pp. 3769-3776, 2003.

[18] S. Ghosh, Z. Abbas, S. Dasari, and A. K. Patra, "Luminescent $\mathrm{Eu}^{3+}$ and $\mathrm{Tb}^{3+}$ complexes of 4aminophenyl terpyridine (ptpy): Photophysical aspects, DNA and serum protein binding properties," J. Lumin., vol. 187, pp. 46-52, 2017. 